\title{
PREFÁCIO MÉXICO
}

\section{EL TRABAJO COLECTIVO DEL SEMINARIO PERMANENTE "ENTRAMADOS COMUNITÁRIOS Y FORMAS DE LO POLÍTICO" PARA EL DOSSIER “POR UNA SOCIOLOGÍA DESDE ABAJO"}

\author{
Raquel Gutiérrez, Lucia Linsalata y Mina Lorena Navarro
}

En febrero de 2019 en la ciudad de Puebla, llevamos a cabo el "Conversatorio Internacional Brasil-México: Por una sociología desde abajo: el papel de la metodología de campo en la investigación sobre formas no capitalistas de reproducción de la vida". En él participamos más de veinte investigadores de la Universidade Federal Fluminense de Brasil y del Instituto de Ciencias Sociales y Humanidades (ICSyH) de la Universidad Autónoma de Puebla (BUAP).

En dicho espacio pudimos compartir las distintas miradas, acercamientos y trabajos que venimos desarrollando en nuestras respectivas latitudes. En nuestro caso, las investigaciones que presentamos hacen parte del Seminario de Investigación de Entramados Comunitarios y Formas de lo Político ${ }^{1}$, una comunidad de trabajo e investigación con sede en el Posgrado de Sociología del ICSyH la BUAP, donde desde 2011, hemos cultivado una perspectiva que enfoca la atención en la variopinta y polimorfa manera en que diversos colectivos humanos, indígenas y no indígenas, se empeñan en luchar de manera cotidiana y extraordinaria para garantizar las condiciones materiales y simbólicas de su propia (re)producción, mediante prácticas políticas que llamamos producción de lo común.

Este encuentro fue profundamente útil para preguntarnos ¿qué implica construir una sociología desde abajo? en su dimensión epistemológica, metodológica, teórica y política y, a la luz de los conocimientos situados e intencionados que venimos produciendo en distintas geografías para comprender e intervenir nuestras propias realidades.

Ante la riqueza de esta encuentro, surgió la propuesta de nuestrxs queridxs Ana Maria Motta Ribeiro y Hugo Belarmino de Morais de reunir algunos de los trabajos y presentarlos conjuntamente en el Dossier "Por una Sociología desde Abajo" que aquí presentamos.

El apartado de los trabajos del Seminario de Entramados Comunitarios y Formas de lo Político presentamos, comienza con el artículo "Co-producir común desde la investigación social. Reflexiones a partir de lo aprendido en una experiencia de mapeo participativo con comités de agua 
del Municipio de Cuetzalan del Progreso, México”, en el que Lucia Linsalata, Sandra Rátiva, Juliana Gomez y Kevin Hernández presentan un ejercicio de sistematización de lo aprendido en un intenso proceso de investigación de campo. Cuatro son los ejes de problematización que les autores presentan en torno al sentido y a las formas de la investigación comprometida que han atravesado y tensionado el proceso colectivo de investigación: 1) la tensión por superar en todo momento del proceso de investigación el problema del extractivismo académico; 2) el potencial político y epistemológico del mapeo como técnica de intervención en campo y práctica de co-producción de narrativas críticas y conocimientos; 3) el transito desde la realización del proyecto a la construcción de una agenda política de largo plazo con los aliados encontrados en el camino; 4) las dificultades del trabajo de co-investigación y escritura colectiva y la búsqueda vital por salir de la dinámica individualizante e individualizada al que nos confina el trabajo académico institucional.

Como parte de los resultados de su investigación de tesis de maestría en Sociología, el texto "La dinámica extractiva del capital como amenaza para la reproducción de la vida. Algunas reflexiones desde la ecología política y el marxismo en torno a la noción de "proyectos de muerte" de Francisco Javier Hernández Hernández, destaca la existencia de un conjunto de projectos extractivos en toda la América Latina que son clasificados como "proyectos de muerte". Desde una perspectiva de la ecología política y del marxismo, el autor presenta una reflexión sobre el modo como el capital gestiona, transforma y destruye la vida humana y no-humana para garantizar la lógica del valor, con consecuencias socio-ecológicas muy destructivas. Así, defiende la posibilidade de recuperar la noción dicotómica vida-muerte para compreender criticamente como la denominación "projectos de muerte" puede significar más que una categoria de lucha o metafórica, una clave de análisis para los procesos de lucha por los territorios y en defensa de la vida en marcha en los diversos países de América Latina.

Le sigue el artículo de Úrsula Hernández Rodríguez, quien en su conocimiento profundo de las luchas antiextractivistas del territorio oaxaqueño en el sureste de México, muestra la experiencia de los habitantes de la región de los Valles de Oaxaca contra los proyectos de minería a cielo abierto. En particular se centra en San José del Progreso, un caso paradigmático en la región, puesto que materializa y visibiliza el impacto social que la actividad extractiva genera en las comunidades-territorios donde se establece. A partir de esta experiencia, en el contexto de la disputa por la tierra-territorio y los bienes naturales, se hacen visibles las distintas construcciones territoriales y el carácter antagónico que tienen las narrativas y modos de concebir y habitar el territorio de las luchas en defensa y cuidado de la vida. 




Los documentos que presentan Diego Castro, Claudia López y Claudia Cuellar abordan dos campos de problemas dentro de un marco general. El marco general lo constituye el desconcierto y la dificultad práctica de mantener la iniciativa comunitaria y popular simultánea a la consolidación de proyectos progresistas en dos países muy distintos: Uruguay y Bolivia. Los dos campos de problemas abordados son los siguientes: el primero reflexiona en torno a la pertinencia de recuperar en las experiencias de las luchas pasadas los rasgos más plenamente anticapitalistas, los anhelos emancipatorios más profundos; los cuales, por lo general resultaron bloqueados y fueron tendencialmente borrados en las narrativas dominantes de los sucesos históricos. En diálogo con la perspectiva de Walter Benjamin e indagando profundamente en las luchas uruguayas del último siglo, Diego Castro recupera lo que él llama los anhelos y prácticas de "los vencidos al interior de los vencidos" avanzando desde ahí a una crítica a las estrategias políticas de izquierda centradas en la toma/ocupación del poder estatal. El trabajo de Castro resulta interesante en el actual contexto de declive del progresismo latinoamericano, en tanto alumbra los diversos modos en que ocurrió el proceso de sustitución y desplazamiento de la fuerza social activada en diversas constelaciones de luchas previas que se articularon, a la postre, en regímenes progresistas que echaron a andar renovados proyectos extractivos. Proyectos progresistas hoy en crisis.

El segundo campo de problemas consiste en indagar en los renovados procesos de lucha anti-extractivista y en defensa de la vida, protagonizados principalmente por mujeres que sostienen la vida en diversos territorios de la geografía boliviana. Los trabajos de Claudia López y Claudia Cuellar presentan reflexiones sobre las novedades políticas que exhiben las luchas actuales en defensa de la vida tanto en la Reserva Natural de Tariquía, al sur de Bolivia, como en diversas regiones de las tierras bajas del Oriente del país.

Todos los documentos comparten ciertas perspectivas de fondo que son parte de los ejes básicos que nutren la mirada cultivada en el Seminario permanente Entramados comunitarios y formas de lo político. En primer lugar, para entender los contenidos más íntimos de las luchas sociales rastreamos los múltiples y diversos modos en que las tramas comunitarias situadas igualmente diversas- se afanan para garantizar su propia auto-reproducción. Diversos rasgos se conjugan en tales acciones: gestión, uso y defensa de recursos materiales disponibles (agua, tierra, bosque, etc.) a fin de garantizar usos y fines acordes con las prácticas y conocimientos que organizan la propia trama comunitaria; esto es, recursos materiales que son gestionados y usufructuados de acuerdo a conocimientos y formas de auto-regulación interna a la propia trama garantizando una específica forma de politicidad: capacidad política de producción y gestión de la riqueza disponible para garantizar la autorreproducción de la trama comunitaria. Desde este punto 


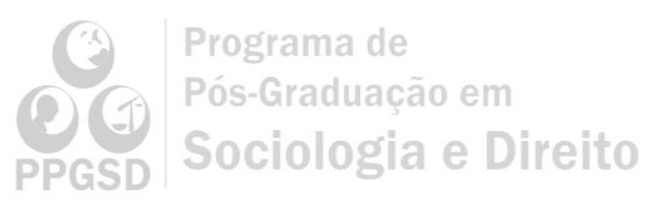

de partida rastreamos, en segundo lugar, las diversas formas en que tales tramas comunitarias son agredidas y despojadas de su autonomía política que, insistimos, consideramos que se funda en la disposición de algunos medios de existencia; es decir, en un conjunto -en ocasiones abundante, en otras escaso- de bienes materiales que garantizan la auto-reproducción de la vida colectiva.

Desde esta mirada y, tal como insiste Claudia Cuellar que sigue el argumento de Silvia Federici en el célebre Calibán y la Bruja, para las mujeres de las tierras bajas de Bolivia, el régimen progresista boliviano se presentan como una alianza entre antiguos terratenientes, nuevas élites políticas gubernamentales de "izquierda", empeños agroindustriales por ampliar áreas de cultivo y rentabilidad de sus actividades y proyectos de producción de energía a gran escala y de construcción de carreteras. Si se toma en cuenta el "pacto patriarcal" que está en el cimiento de tal alianza progresista, la resistencia y rebelión actual de las mujeres de tierras bajas adquiere su sentido más plenamente emancipador: se defiende la vida colectiva contra la ofensiva del capital que busca re-colonizar territorios para sustraer su control y usufructo a las comunidades que las habitan.

Por su parte, Claudia López indaga con mayor profundidad en la manera cómo tal pacto patriarcal que sostiene la ofensiva re-colonizadora del capitalismo extractivista ha sido puesto en crisis por las luchas de las mujeres en Tariquía. Su perspectiva muestra no sólo la potencia - y la enorme dificultad - de estas luchas renovadas de las mujeres que habitan territorios amenazados por la expansión petrolera, sino que se afana por mostrar los contenidos anticapitalistas en sus esfuerzos anti-patriarcales que, además, se empeñan en revitalizar la trama comunitaria que habitan, sustrayéndola de la tutela estatal construida a partir de la corporativización de las anteriormente independientes organizaciones sindicales campesinas. Sus hallazgos sobre cómo se ponen paulatinamente en crisis las organizaciones sindicales "mixtas" a partir de la alianza inmediata y profunda entre las mujeres de Tariquía para rechazar la destrucción de sus territorios, abre un hilo fértil para entender el actual contenido anticapitalista de las luchas antipatriarcales que se desarrollan en Bolivia.

A manera de conclusión del Dossier, Raquel Gutierrez y Mina Lorena Navarro nos proponen algunas síntesis parciales del aprendizaje colectivo del Seminario "Entramados comunitários y formas de lo político" desde hace varios años: 1) lo comunitario no es necesariamente indígena y lo indígena no es necesariamente comunal; 2) lo comunitario es una relación social y, por tanto, se produce, se practica y se cultiva; 3) la vida es interdependiente y la producción de lo común es un modo colectivo de renovar y disputar su gestión y 4) las luchas renovadas de las mujeres en defensa de la vida y contra todas las violencias machistas, y el entre 
mujeres como una forma de producción de lo común, están poniendo en crisis los mundos mixtos de la vida pública y privada y relanzando otros términos de gestión de la interdependencia. Estas claves son apuestas y esfuerzos para comprender, documentar, apoyar y participar de diversas prácticas y luchas - indigenas y/o populares - de matriz comunitaria en contra de la amalgama capitalista, patriarcal y colonial.

Mencionar, finalmente, que estos trabajos se proponen nutrir la discusión acerca de los horizontes políticos comunitarios y populares que anidan y se despliegan en las luchas concretas y situadas en defensa de la vida. Consideramos que atender y reflexionar sobre los contenidos y sentidos que animan las luchas anti-extractivistas contemporáneas, en particular las protagonizadas por mujeres, es un camino fértil para salir del desconcierto producido por la actual crisis de los progresismos que, en realidad, según insiste Claudia López, es la crisis de un modo de expropiar la fuerza colectiva. Nosotras consideramos que de lo que se trata es de recuperarla y en eso ponemos el empeño.

Puebla, Pue., México, 23 de agosto de 2019. 